\title{
Ethnomedicinal Plants Used for the Treatment of Malaria in Malaka, West Timor
}

\author{
Maximus M Taek ${ }^{1 *}$, Bambang Prajogo $\mathrm{EW}^{2}$, Mangestuti Agil ${ }^{2}$ \\ 'Department of Chemistry, Faculty of Mathematics and Natural Sciences, Widya Mandira Catholic University, Kupang, INDONESIA. \\ 2Department of Pharmacognosy and Phytochemistry, Faculty of Pharmacy, Airlangga University, Surabaya, INDONESIA.
}

\begin{abstract}
Objective: This study aims to document ethnomedicinal plants used in the traditional treatment of malaria in some areas of Malaka District in West Timor, Indonesia. Methods: Semi-structured questionnaire interviews and focused group discussion were used to gather ethnomedicine data from traditional healers and people who know about traditional medicines. The study involved 38 informants, 30 women and 8 men, aged between 32-90 years, from 10 villages in 4 sub-districts. Results: A total of 44 plants species belonging to 25 families used for the treatment of malaria in some area of Malaka. Calotropis gigantea, Cleome rutidosperma, and Physalis angulata were the most cited for oral administration. Jatropha curcas, Garuga floribunda, and Calotropis gigantea were the most used by massage method. For the bathing method of treatment, Tamarindus indica was the most cited. Conclusion: Indigenous people of Malaka in West Timor have a culture of ethnomedicine for malaria treatments that is mainly based on local plants, and is transmitted from one generation to the next by oral instructions.
\end{abstract}

Key words: Ethnomedicine, Medicinal plants, Antimalarial, West Timor.

Key message: Antimalarial plants across generations in Malaka people of West Timor, Indonesia have been explored well. Therefore, the data is very potential to be further developed as new materials for antimalarial drug developments.

Correspondence

Maximus M Taek, Department of Chemistry, Faculty of Mathematics and Natural Sciences, Widya Mandira Catholic University, Jln. Jend. Achmad Yani 50-52 Kupang 85115, INDONESIA.

Phone: +6282245811193

Email: maximusmt2012@gmail.com

DOI: 10.5530/jyp.2018.10.42

\section{INTRODUCTION}

Malaria is caused by blood parasites, Plasmodium falciparum, P. ovale, P. malariae, $P$. vivax, and $P$. knowlesi. ${ }^{1}$ Until now, malaria is still a health problem worldwide, especially in tropical countries like Africa and Asia. About 3.3 billion people worldwide are at risk of malaria. In 2013, there were about 216 million cases and 315,000-689,000 malaria deaths. Globally, $90 \%$ of all deaths from the disease were recorded in Africa, mainly on children under five years of age. ${ }^{2}$ Malaria is an example of classical diseases that greatly affects the productivity of individuals, families and society. ${ }^{3}$

The territory of Timor, Indonesia has long been frequently attacked by various dangerous diseases such as malaria and cholera; and malaria is the major infectious disease that often affects the people, especially in Belu and Malaka districts. Until this time, Malaka district is a high endemic area of malaria in Indonesia. At present, indigenous people in this area still often seek traditional treatment with various medicinal plant materials to treat malaria, either as the first choice, or the early treatment before going to the hospital, or even as an alternative when the hospital treatment has not provided healing. ${ }^{4}$

An efficient management of malaria requires the use of all resources available, accessible, and culturally acceptable. Currently, the programs against malaria integrate several areas including the prevention and the treatment. Various research results indicated that the traditional community of almost all cultures has long developed ways to prevent malaria attacks and treat people with the disease. The approaches developed in a traditional medicine culture to manage malaria disease are based on the local knowledge of the community about malaria. ${ }^{5}$

Since the declaration of World Health Organisation (WHO) Alma-Ata in 1978, the WHO has recognized and encouraged the use of resources of medicine and a traditional pharmacopeia in primary health care. Worldwide, the traditional pharmacopeia has been continuing to play a critical role in the discovery of new molecules of therapeutic interests and particularly in the fight against malaria. With the emergence of resistance of the parasite $P$. falciparum to conventional synthetic drugs, the research for new therapeutic targets by ethnopharmacological methods is an interesting approach, including the search for new antimalarial drugs. ${ }^{6}$

Publications of the ethnomedicine researches on the treatment of malaria in Timor island were not found. Mali in 1991 conducted a study to document the wild plants used in various prescriptions for various diseases by traditional healers in Belu region. The results of the study did not indicate some prescriptions intended for the treatment of malaria. ${ }^{4}$ Our study was conducted in the lowland region of Malaka, located on the southern coast of the Timor island. This area has a more extended rainy season than Belu in the north. Until now, there has not been published data about medicinal plants used to treat malaria in this region. Therefore, this study was conducted to document ethnomedicinal plants used in the traditional treatment of malaria in some areas of Malaka District. The results of this study are expected to be a database for further exploration of these antimalarial plants to find new antimalarial substance(s), or, to support the primary health care.

\section{METHODS}

The study area

The district of Malaka is in the southern part of the island of Timor $\left(9^{\circ} 34^{\prime}\right.$ S, $124^{\circ} 54^{\prime}$ E), directly adjacent to Republica Democratic de Timor Leste, and separated from Australia by the Timor Sea (Figure 1). Some areas 
of Malaka lie on the lowland, and some on the highland. The district of Malaka is divided into 12 sub-districts. The survey was conducted from April to July 2017 in the lowland region of Malaka, involved 10 villages in 4 sub-districts (Malaka Tengah, Malaka Barat, Weliman, and Wewiku). There are two rainy seasons and one dry season in this area. Three major ethnic groups are native to the area: Tetun, Dawan, and Marae. Tetun is the most massive ethnic, and this study was conducted on the people of this ethnicity.

\section{Ethnomedicinal survey}

Full oral semi-structured questionnaire interviews and focused group discussion were used to gather ethnomedicine data from traditional healers and people who know traditional medicine. The questions were focused on the demographic profile of the traditional healer and their knowledge of medicinal plants used in to fight malaria. Traditional healers identities consisted of, i.e. general identities (name, sex, age, educational level, language ability), knowledge origin, diagnosis method(s), and remedy (local names of the plants, used parts, the source of plants materials, remedy formulation, route of administration, dosage, and duration of the treatment).

Plant samples were collected on the field and pictures were taken to aid the identification. The identification of the plants was made firstly by comparing the plant's local name with the list of tree and shrub names from Timor, ${ }^{7}$ and by comparing the picture of the plant taken on the field with the image of the plant in various plant databases available online. The herbs were also identified and verified by a botanist of the Biology Departement of Widya Mandira Catholic University in Kupang, Indonesia.

\section{Data analysis}

The importance of each plant in the treatment of malaria was assessed by the relative frequency of citation (RFC) calculated using the following formula: ${ }^{8}$

$$
\mathrm{RFC}=\frac{\mathrm{FC}}{\mathrm{N}}
$$

where FC was the number of people who mentioned the use of the species and $\mathrm{N}$ the total number of individuals.

\section{RESULTS}

\section{Demographic data and knowledge about malaria}

Investigations were conducted with 38 informants who knew antimalarial plants including 30 women and 8 men. The culture of plants used was received from parents and by personal experiences, including dreams or enlightenment of the ancestors, and learning from other traditional healers (Table 1).

Traditional healers in the study area have classified malaria as a "hot body or high body temperature" disease, with some primary clinical signs that include fever, chills, and spleen enlargement. According to their local knowledge, malaria is caused mainly by eating or drinking too many sweet foods or beverages. The foods are sugarcane, banana, fried- or roasted corn, and young coconut. Otherwise, it is also caused by being too long in the water (rice fields, an excessive bathing, under the rain), under the hot sun, and because of tiredness.

The malaria treatment is done in three ways such as massage, bathing, and taking oral medicines. All three are done by using ingredients of medicinal plants. These three ways of treatment can be applied at once to the patient, but most healers have recommended massage and bathing, especially for infants and children. On average, the treatment is performed for at least three to four days.

\section{Plants used for the treatment of malaria}

Informants mentioned a total of 44 plant species belonging to 25 families for curing malaria (Table 2). Fabaceae/Leguminosae were the most represented family with six species, followed by Apocynaceae, Euphorbiaceae, and Rutaceae with four species each. Also, 21 families were represented by only one species each (Figure 2). Most of those medicinal plants are wild and non-cultivated plants, which obtained from forests or fields around the village (75.00\%). Only a few plants are cultivated in the home garden (20.45\%), such as Carica papaya, Averrhoa bilimbi, Basillicum polystachyon, Ocimum americanum, Ruta graveolens, Citrus aurantifolia, Solanum lycopersicum, Acorus calamus, and Sesbania grandiflora. Some of them obtained from the traditional local market (4.55\%), i.e. Allium cepa (onion) and A. sativum (garlic) (Figure 3). Twenty two (22) species were used in various prescriptions for oral administration, 32 were used for massage, and 6 were used as ingredients of bath water. One species can be used in more than one way of treatment (Figure 4).

The calculated RFC indicated that species such as Calotropis gigantea, Cleome rutidosperma, Physalis angulata, Jatropha curcas, Garuga floribunda and Tamarindus indica were the most used in the traditional medicine for the treatment of malaria in Malaka District. C. gigantea $(\mathrm{RFC}=0.53)$, C. rutidosperma $(\mathrm{RFC}=0.45)$ and $P$. angulata $(\mathrm{RFC}=0.45)$ were the most used for oral administration. J. curcas (RFC=0.61), G. floribunda $(\mathrm{RFC}=0.55)$, and $C$. gigantea $(\mathrm{RFC}=0.53)$ were the most used to treat malaria patient by the massage method. And, T. indica $(\mathrm{RFC}=0.47)$ was the most used in the bathing method of the treatment (Table 2).

The parts of plants used could be either the leaves (52\%), stem bark $(18 \%)$, roots $(14 \%)$, bulbs $(2 \%)$, cloves $(4 \%)$, seeds $(2 \%)$, heartwood (2\%), rhizome (2\%), fruit (2\%), or whole plants (4\%) (Figure 5). The

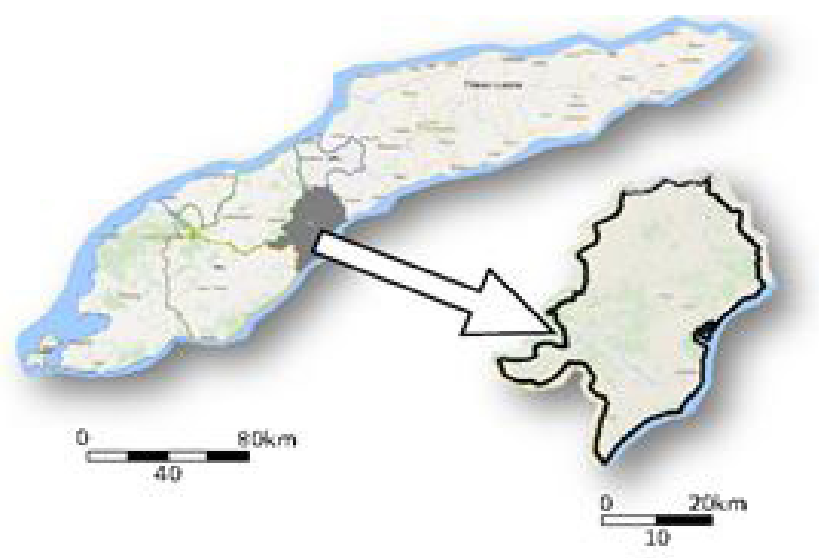

Figure 1: Map of Timor island showing the study area, District of Malaka.

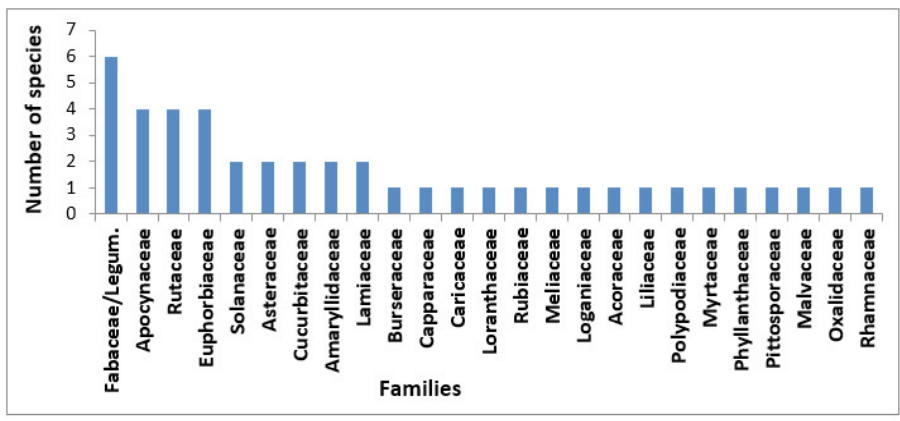

Figure 2: Antimalarial plants species distribution among families 


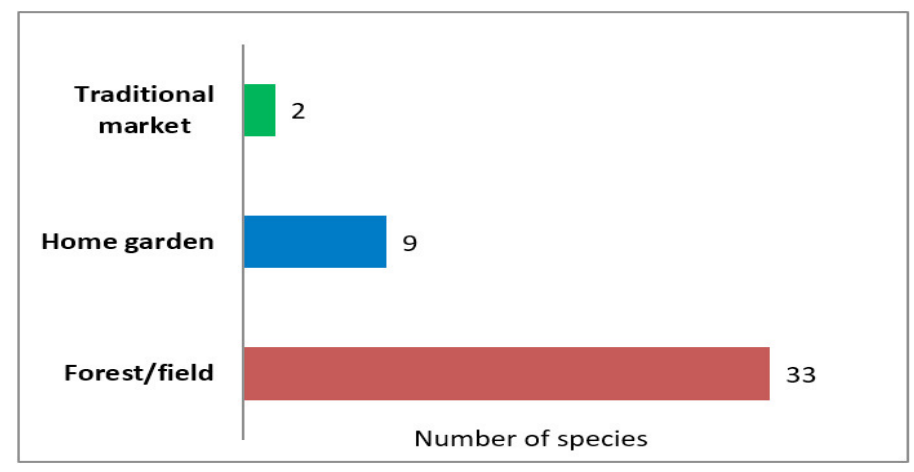

Figure 3: Source of antimalarial plants species used by traditional healers in Malaka

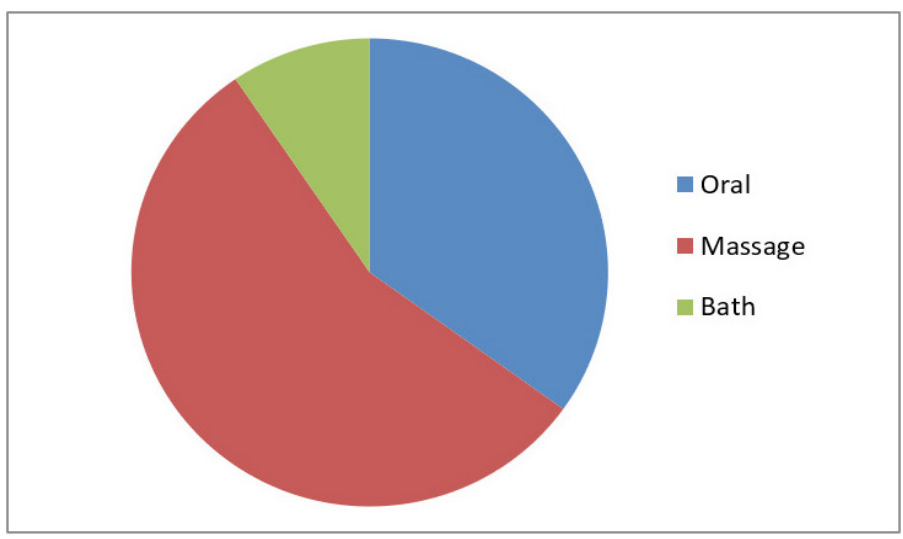

Figure 4: Methods of remedies administration in the treatment of malaria in Malaka

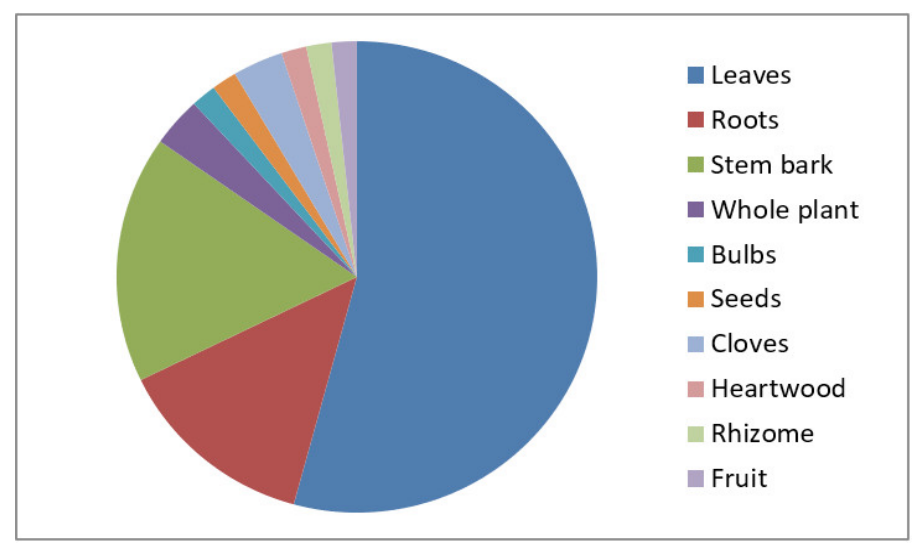

Figure 5: Proportion of different plants parts used in the treatment of malaria in Malaka

recipes for remedy could be a single or a combination of various species of plants or plant parts. To prepare a plant material into medicine, it was processed simply, for example crushing and mixing with a little amount of water or oil for massage; soaking the whole or ground for a mixture of bath water; or boiling with water for a drink. The recipes for a drink or oral administration, in general, the amount of plant material and the volume of water used were not precisely defined. The dosage was ranged from two to three doses per day for the oral administration, and one to twice per day for massage and bathing methods.
Table 1: Demographic data of the informants $(N=38)$

\begin{tabular}{cccc}
\hline & Group & N & $\%$ \\
\hline \multirow{2}{*}{ Gender } & Male & 8 & 21.05 \\
Age & Female & 30 & 78.95 \\
& Less than 40 years & 1 & 2.63 \\
& $41-50$ & 3 & 7.89 \\
Educational background & $51-60$ & 7 & 18.42 \\
& More than 71 years & 20 & 18.42 \\
& Illiterate & 29 & 76.32 \\
Language ability & Primary level & 3 & 7.89 \\
& Secondary level & 3 & 7.89 \\
Profession & Tetun (local languange) & 30 & 78.95 \\
& Tetun and Indonesian & 8 & 21.05 \\
& Farmer or household & 37 & 97.37 \\
Mode of acquisition of & Officer & 1 & 2.63 \\
the knowledge & Inheritance & 31 & 81.58 \\
& Personal experience & 7 & 18.42 \\
\hline
\end{tabular}

\section{DISCUSSION}

Methods of the disease's treatments that developed in a traditional medical culture were based on the local knowledge of the people about the disease. Indigenous people in Malaka thought that the causes of malaria are sugary (sweet) foods and beverages, being too long in wet places or under the sun, and tiredness. Such understanding was also found in indigenous societies in Africa. ${ }^{9}$ In our study, no informants have linked malaria with mosquito bites. Mosquitoes were considered as insects that make uncomfort feelings because of their sounds and bites, but were not regarded as the carriers of malaria.

Indigenous people in Malaka were very familiar with the term "malaria," but they classified malaria just as "hot body" or fever. Therefore, most treatments given to malaria patient were the simple home-based management of illness, such as massage and bathing. Traditional healers usually help malaria patient with massage and bathing as the first option to reduce heat. The ingredient for a drink is generally given if those two ways of treatment did not become successful in healing.

This study revealed that plants of families Fabaceae/Leguminosae, Apocynaceae, Euphorbiaceae, and Rutaceae were particularly well known by the interviewees. The plants were widely used and have contributed to malaria treatments, used either alone or in combination with other species. The bibliographic studies indicated that some of the plants recorded in this study were also used for the treatment of malaria in other parts of Indonesia as well as in other countries. Alstonia scholaris, Blumea balsamifera, Carica papaya, Cassia fistula, C. siamea, Morinda citrifolia, Momordica charantia, Phylanthus niruri, and Strychnos ligustrina, were also used as a traditional antimalarial in Java and Sumatra. ${ }^{10,11}$ The traditional usage of G. floribunda, Zyzyphus timorensis, Wrightia calycina, Wrightia pubescens, Syzygium cumini, and Pittosporum timorense in the treatment of malaria is reported here for the first time.

Daily consumption of Carica papaya leaves as a green, vegetable and herbal decoction is common in some parts of Indonesia in order to prevent malaria. ${ }^{12}$ C. papaya leaf extract showed good in vivo and in vitro antimalarial activities. ${ }^{13,14}$ Ocimum sp., P. niruri, Aegle marmelos and $M$. charantia were also used in India as antimalarials; and showed good 
Table 2: Plant species used in the treatment of malaria in Malaka

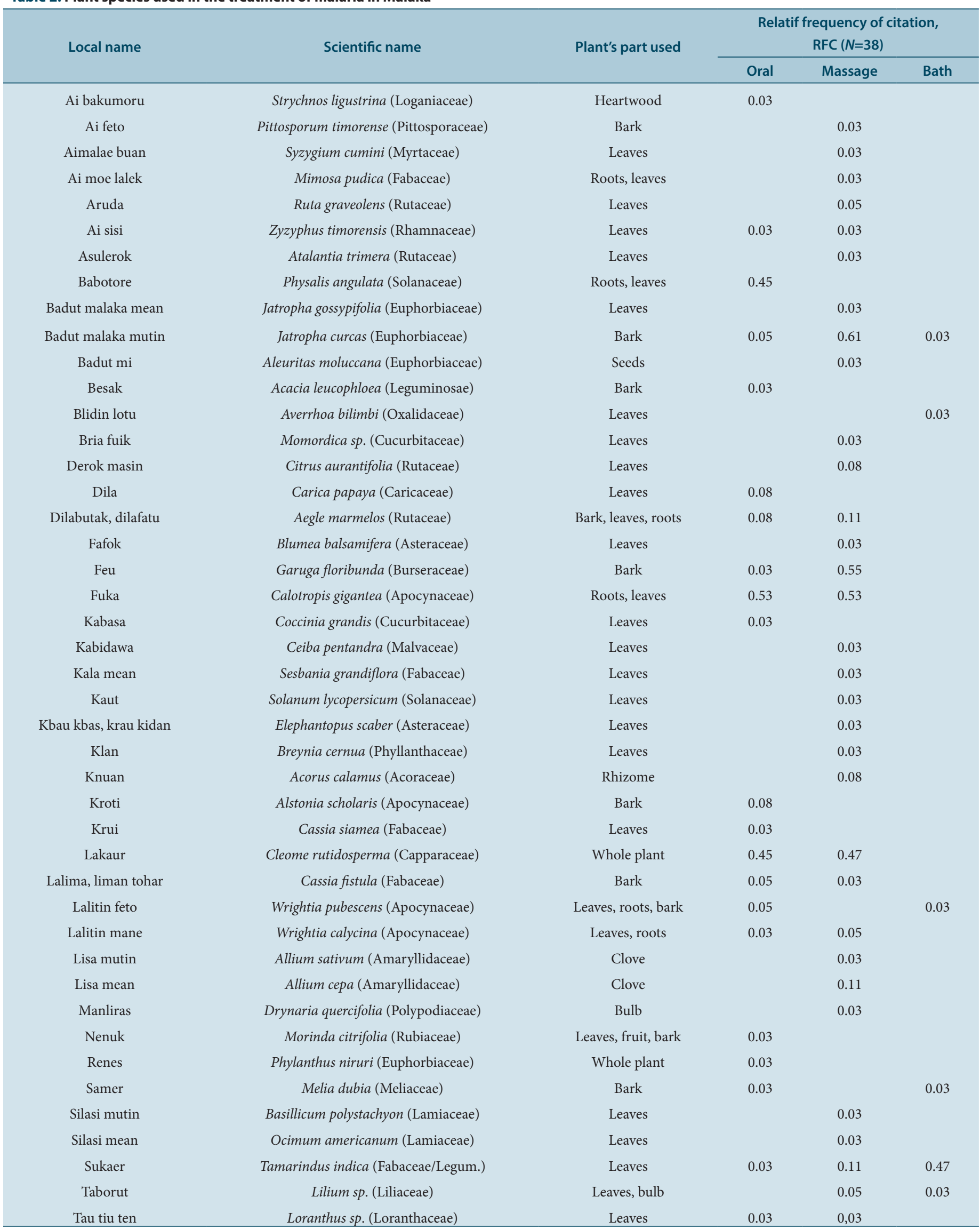


antiplasmodial activity against $P$. falciparum in vitro. ${ }^{14,15}$ Three species in this research with the highest RFC values for oral use, namely C. gigantea, C. rutidosperma and P. angulata are also known as traditional antimalarial medicine in Africa, Asia, and America. In the evaluation of their antimalarial activity, the extracts of $C$. gigantea and $P$. angulata showed a strong activity $\left(\mathrm{IC}_{50}\right.$ value $<10 \mu \mathrm{g} / \mathrm{mL}$ ) against $P$. falciparum. An ethanolic extract of $C$. rutidosperma showed a moderate activity $\left(\mathrm{IC}_{50} 34.4 \mu \mathrm{g} / \mathrm{mL}\right.$ ), although the aqueous extract was found to be inactive $\left(\mathrm{IC}_{50}>100 \mu \mathrm{g} / \mathrm{mL}\right) .{ }^{16-19} \mathrm{~J}$. curcas and T. indica are also used in the traditional treatment of malaria in Africa. Studies on the antimalarial activity of $J$. curcas leaf and T. indica bark and fruit extracts showed that they both were active to inhibit the growth of Plasmodium. ${ }^{20,21,22}$

The antimalarial activity of various plant extracts is contributed by various secondary metabolite compounds such as terpenoids, iridoids, alkaloids, cardenolides, flavonoids, coumarins, phenolics, polyacetylenes, xanthones, quinones, steroids, lignans, tannins and saponins contained in any plant extract. ${ }^{23}$

Most plant materials used were prepared for the treatment by massage (56\%), followed by drink (34\%), and bath (10\%). Medicinal plants used for massage and bath such as G. floribunda, C. gigantea, J. curcas, T. indica and C. rutidosperma are considered as "cold" plants that work to lower the body's high temperature. However, there are also medicinal plants for massage that are hot, such as Ruta graveolens, Zyzyphus timorensis, Acorus calamus, Basillicum polystachyon, Ocimum americanum, Allium cepa, and $A$. sativum, which helps to increase body temperature and forces the body to produce sweat, so the temperature of the body will fall back to normal. Many plants used for the oral administration have bitter taste. Indigenous people in Malaka thought that malarial medicine must be bitter, as opposed to sweety foods and drinks that they consider to be the cause of malaria. This concept of drug-disease disagreement properties (cold-hot, bitter-sweet) seems like a basic- and universal concept shared by many traditional systems of medicine around the world. ${ }^{24}$ Most of the plants used as medicines were obtained from forests or fields around the village (75\%). The indigenous people believe that wild- or uncultivated plants have more "healing power" (efficacy) than cultivated plants. Some studies have linked this concept with the differences in environmental pressures faced by plants. Because of biotic and abiotic stresses, such as temperature, light intensity, herbivory- and microbial attacks, plants generated defensive mechanisms, triggering many complex biochemical processes. Non-cultivated plants generally face higher environmental pressures than cultivated plants, and then, they often produce secondary metabolites that have better pharmacological properties. ${ }^{25}$

Leaves were the most used part of the plant (52\%). This fact deals with "ai tahan" (means leaf), the local term used by the Tetun ethnic community to mentions their traditional medicines. In a scientific explanation, leaves are the main photosynthetic organ and, therefore, tanks and photosynthesizes exudates containing secondary bioactive compounds that protect against external aggressions. These compounds have medicinal values for human body. ${ }^{26}$

In this study, about $90 \%$ of informants are aged over 50 years old. Consequently, there is an urgent need for documentation of their invaluable knowledge. The educational level of the informants was low; many traditional healers were illiterate (76.32\%), and consequently could not document their practice. The inheritance $(81.58 \%)$ was the major source of knowledge acquisition, and therefore, it is advocated that the knowledge of the disease acquired by inheritance must be documented in writing for a future generation.

\section{CONCLUSION}

Indigenous people of Malaka in West Timor have a culture of ethnomedicine for malaria treatments that is mainly based on local plants and is transmitted from one generation to the next by oral instructions. The investigation results have identified 44 species commonly used in traditional medicines of the people of Malaka to treat malaria. These medicinal plants may probably contain undiscovered antimalarial properties, which can serve as a template for the production of antimalaria drugs from indigenous plants in Malaka. The recording and preservation of the local knowledge in writing have become a vital scientific and cultural importance. This study also highlighted the potential sources for the development of new and local antimalarial drugs from indigenous medicinal plants found in Malaka.

\section{ACKNOWLEDGEMENT}

We thankful to the Directorate of Research and Community Service, Ministry of Research, Technology and Higher Education, Republic of Indonesia, for the financial support. We are indebted to all the tribal informants who have participated and provided their valuable knowledge relevant to this work.

\section{CONFLICT OF INTEREST}

We declare that we have no conflict of interest.

\section{ABBREVIATIONS}

RFC: Relative Frequency of Citation.

\section{REFERENCES}

1. Roy A, Thamizhmani R, Raj RV, Pulikkottil S. Mixed infection of Plasmodium falciparum and Plasmodium vivax and unusual presentations of vivax malaria in the Andaman Islands-case reports. Asian Pac J Trop Dis. 2015:5(5):418-20.

2. World Health Organization. World Malaria Report 2014. Geneva, Switzerland: WHO Press. 2014

3. Saxena S, N Pant, DC Jain, RS Bhakuni. Antimalarial agents from plant sources. Current Sci. 2003:85(9):1314-26

4. Maximus M, Mali S. Plants in ai tahan; traditional medicine of the Tetun ethnic community in West Timor Indonesia. Proc $7^{\text {th }}$ Annual Basic Science Int. Conf. 7-8 March. 2017;71-6.

5. Idowu OA, Mafiana CF, Sotiloye D. Traditional birth home attendance and its implications for malaria control during pregnancy in Nigeria. Transactions Royal Soc of Trop Med Hyg. 2008;102(7):679-84.

6. World Health Organization. Factsheet No. 134. Traditional Medicine. Geneva, Switzerland: WHO Press. 2008.

7. Drees EM. List of tree and shrub names from Timor. Balai Penyelidikan Kehutanan, Bogor. 1950;20-4.

8. Agbodeka K, HE Gbekley, SD Karou, K Anani, A Agbonon, T Tchacondo, et al. Ethnobotanical study of medicinal plants used for the treatment of malaria in the plateau region, Togo. Pharmacognosy Res. 2016;8(1):S12-S8.

9. Nyamongo IK. Lay people's responses to illness: an ethnographic study of antimalaria behavior among the Abagusii of Southwestern Kenya. Dissertation, University of Florida. 1998.

10. Trimurningsih S, Matsuura H, Takahashi K, Yamasaki M, Yamato O. Evaluation of the inhibitory activities of the extract so Indonesian traditional medicinal plants against Plasmodium falciparum and Babesia gibsoni. J Vet Med Sci. 2005;67(8):829-31.

11. Abdillah S, Tambunan RM, Sinaga YM, Farida Y. Ethnobotanical survey of plants used in the traditional treatment of malaria in Sei Kepayang, Asahan of North Sumatera. Asian Pacific J Trop Med. 2014;S1:104-7.

12. Elfahmi E, Woerdenbag HJ, Kayser O. Jamu: Indonesian traditional herbal medicine towards rational phytopharmacological use. J Herb Med. 2014;4(2):51-73.

13. Okpe O, Habila N, Ikwebe J, Upev VA, Okoduwa SI, Isaac OT. Antimalarial Potential of Carica papaya and Vernonia amygdalina in Mice Infected with Plasmodium berghei. J Trop Med. 2016. 8738972.

14. Venkatesalu V, Gopalan N, Pillai CR, Singh V, Chandrasekaran M, Senthilkumar A, et al. In vitro anti-plasmodial activity of some traditionally used medicinal plants 
against Plasmodium falciparum. Parasitol Res. 2012;111(1):497-501.

15. Kamaraj C, Kaushik NK, Rahuman AA, Mohanakrishnan D, Bagavan A, Elango G, et al. Antimalarial activities of medicinal plants traditionally used in the villages of Dharmapuri regions of South India. J Ethnopharmacol. 2012;141(3):796-802.

16. Wong SK, Lim YY, Abdullah NR, Nordin FJ. Assessment of antiproliferative and antiplasmodial activities of five selected Apocynaceae species. BMC Complement Altern Med. 2011;11(1):11-3.

17. Kffuri CW, Lopes MA, Ming LC, Odonne G, Kinupp VF. Antimalarial plants used by indigenous people of the Upper Rio Negro in Amazonas, Brazil. J Ethnopharmacol. 2016;178:188-98.

18. Ruiz L, Maco M, Cobos M, Gutierrez-Choquevilca AL, Roumy V. Plants used by native Amazonian groups from the Nanay River (Peru) for the treatment of malaria. J Ethnopharmacol. 2011;133(2):917-21.

19. Bose A, Smith PJ, Lategan CA, Gupta JK, Si S. Studies on in vitro antiplasmodial activity of Cleome rutidosperma. Acta Pol Pharm. 2010;67(3):315-8.

20. Abiodun O, Gbotosho G, Ajaiyeoba E, Happi T, Falade M, Wittlin S, et al. In vitro antiplasmodial activity and toxicity assessment of some plants from Nigerian ethnomedicine. Pharm Biol. 2011:49(1):9-14.
21. Koudouvo K, Karou SD, Ilboudo DP, Kokou K, Essien K, Aklikokou K, et al. In vitro antiplasmodial activity of crude extracts from Togolese medicinal plants. Asian Pac J Trop Med. 2011;4(2):129-32.

22. Mwangi GG, Wagacha JM, Nguta JM, Mbaria JM. Brine shrimp cytotoxicity and antimalarial activity of plants traditionally used in treatment of malaria in Msambweni district. Pharm Biol. 2015;53(4):588-93.

23. Ntie-Kang F, Onguéné PA, Lifongo LL, Ndom JC, Sippl W, Mbaze LM. The potential of anti-malarial compounds derived from African medicinal plants, part II: a pharmacological evaluation of non-alkaloids and non-terpenoids. Malar J. 2014;13(1):81.

24. Heinrich M. Ethnobotany and natural product: the search for new molecules, new treatment of old diseases or a better understanding of indigenous cultures? Current Topics in Med Chem. 2003;3(2):29-42.

25. Pavarini DP, Pavarini SP, Niehues M, Lopes NP. Exogenous influences on plant secondary metabolite levels. Animal Feed Sci and Tech. 2012;176(1):5-16

26. Yeteinw MH, Houessou LG, Lougbégnon TO, Teka O, Tente B. Ethnobotanical study of medicinal plants used for the treatment of malaria in plateau of Allada, Benin (West Africa). J Ethnopharmacol. 2013;146(1):154-63.

Article History: Submission Date : 11-12-2017; Revised Date : 10-02-2018; Acceptance Date : 13-02-2018.

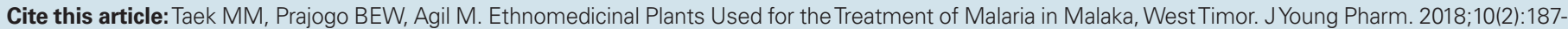
92 